\title{
Developing Phonological Awareness in Blended-learning Language Courses
}

\section{Carmela Dell'Aria ${ }^{1}$ and Laura Incalcaterra McLoughlin ${ }^{2}$}

\begin{abstract}
This study is based on Second Language Acquisition through blended learning and explores the application of new educational technologies in the development of distance education. In particular, the paper focuses on ways to enhance oral, aural, and intercultural skills through learners' engagement, develop authentic social interaction and intercultural awareness in virtual environments and at the same time actively engage the students' powers of perception, communication and reasoning. A speech visualization technology is introduced, specifically tailored to pronunciation training. It provides relevant and comprehensible visual feedback of all three components of speech: prosody-intonation, stress and rhythm. In this paper we stress that the achievement of successful communication should be the main objective of a second language learner, whilst overcoming the foreign accent can be deemed as a secondary goal. A strong or incorrect placement of word stress may impair understanding - from the listener's point of view - of the word(s) being pronounced. On the other hand, acquiring correct timing of phonological units helps to overcome the impression of foreign accent, which may ensue from an incorrect distribution of stressed vs. unstressed stretches of linguistic units such as syllables or metric feet. For these reasons our study looks at how to improve a student's performance both in perception and production of spoken Italian prosodic features, which include the correct position of stress at word level, the alternation of stress and unstressed syllables, the correct position of sentence accent, the generation of the adequate rhythm from the interleaving of stress, accent, phonological rules, and the generation of adequate intonation patterns for each utterance related to communicative functions.
\end{abstract}

Keywords: speech analysis tools, interaction, Italian, blended learning, phonology.

1. Università degli Studi di Palermo, Italy; carmela.dellaria@unipa.it

2. National University of Ireland, Galway, Ireland

How to cite this article: Dell'Aria, C., \& Incalcaterra McLoughlin, L. (2013). Developing Phonological Awareness in Blended-learning Language Courses. In L. Bradley \& S. Thouësny (Eds.), 20 Years of EUROCALL: Learning from the Past, Looking to the Future. Proceedings of the 2013 EUROCALL Conference, Évora, Portugal (pp. 78-85). Dublin/ Voillans: (C) Research-publishing.net. 


\section{Introduction}

The term phonological awareness refers to a general appreciation of the sound structure of spoken words. It is one component of a larger phonological processing system used for speaking and listening. It is developed through a variety of activities that expose foreign language (FL) students to the sound structure of the language and teach them to recognize, identify and manipulate it. Listening skills are an important foundation for the development of phonological awareness and they generally develop first. However, listening in itself is not enough. Therefore, different strategies must be implemented to aid students in becoming alert to sounds. Throughout this paper the expression phonological awareness is used to mean an awareness at all levels necessary to grasp the language system and progress from word and phrase level to sentence level.

This paper discusses aspects of foreign pronunciation in Italian which may affect intelligibility, and reviews a method for teaching prosody implemented experimentally at the National University of Ireland (NUI), Galway in 2012-13 and showing great potential for improving pronunciation practice. As such, it analyzes the intonation of 14 beginner students of Italian enrolled in an online course. Students worked with the assistance of computer technology which allowed them to see (graphically) as well as hear both out-of-context sentences and sentences which were part of coherent discourse-level intonation. We argue that this twostep procedure makes it possible for students to understand and learn how to apply intonation for their real communicative needs. Very often this technology is used to teach or enhance traditional sentence-level pronunciation, encouraging sentence level practice and even focusing on grammatical forms. We further argue that sentence-level practice is insufficient to teach how intonation is used in connected speech.

\subsection{Theoretical framework}

The prosodic system is a "suprasegmental"3 feature of the "paralinguistic" system" and it is considered a basic element which characterizes the real meaning of communication. In current language teaching methodology, suprasegmentals are

3. This term refers to a phonological unit that lasts many segments and stays above them. This is the case of prosodic units such as stress, quantity, tone, syllable, junction, intonation and rhythm.

4. This expression indicates all the events which cannot be analyzed in themselves and are connected with the analysis of suprasegmental features (stress, rhythm, and intonation) and those ones concurrent to the pronunciation (voice volume, elocution speed, hesitation, speechless pauses). 
given very high priority in the pronunciation curriculum (Chun, 1988; Dickerson, 1989; Gilbert, 1984, 1987; McNerney \& Mendelson, 1987; Pennington \& Richards, 1986) and are the subject of a branch of linguistics, called Phonology of Intonation.

According to Cruttenden (1986) the suprasegmentals provide the 'backbone' of utterances; they highlight the information that speakers regard as important (Bolinger, 1986). The intonation resistance to change (Liebermann, 1967) and the deep-rooted prosodic features of L1 are two important factors that impact negatively on the acquisition of intonation in a foreign language. For this reason FL learners are often not aware of any differences in intonation between L1 and L2.

Previous research proves that a prosodic approach can help learners to overcome these problems because it is based on the neural organization of linguistic perception (Gomez et al., 2008), which influences both perception and production of certain distinctions and characteristic of native speakers.

\subsection{The present study}

In this study we introduce multimedia web and speech analysis technology, which highlight the interrelatedness of various aspects of spoken Italian and provide relevant and comprehensible suprasegmental pronunciation training for non-native speakers (NNSs) of Italian. The project is underpinned by the basic principles for designing learning environments within Mayer's (2001) cognitive theory of multimedia learning and Fletcher and Tobias' (2005) argument in favour of visuals within multimedia learning environments: simultaneous involvement of the acoustic and the visual channel helps memory retention. It also takes into account Schmidt's (2001) noticing hypothesis: L2 learners should notice the input in order to transform it into intake for learning.

In our trials, students were not only watching and listening to the audio (visual) material, they also analyzed the "intonational contour" into the target language, noticed the language and provided contrastive association with the corresponding L1 item. We used PRAAT ${ }^{5}$ software, which provides immediate visual feedback on intonation, thereby helping FL learners' apperception. For our experiment, five native (NS) Italian speakers and 14 NNSs (from the Republic of Ireland) served as subjects. The study was designed to obtain preliminary data on the differences in intonation patterns of some sentence types by NS and NNSs. Through the comparison of the NS and NNS sentences, the study aimed at getting evidence of

5. Freely downloadable from http://www.fon.hum.uva.nl/praat/ 
how the exposure to prosodic features through authentic audio (visual) material can affect foreign language prosodic retention.

\section{Method}

\subsection{Experimental design}

A pilot project, Inton.It@, was created by the researchers for fourteen NNSs with different levels of education and integrated as a blended learning experience in the first year of the Diploma in Italian Online (level 7). In the second semester the pilot received a grant from LLP - Grundtvig Visits and Exchanges and later the Diploma in Italian Online was awarded the European Language Label 2013 in Ireland.

The project followed a blended learning approach: material was delivered online in weekly packages; however, on-campus face-to-to-face meetings were also included. It was also based on a communicative and connectivist approach, and learners were encouraged to help each other in the construction of knowledge. Great emphasis was given to collaborative Web 2.0 tools. The methodology provided students with explicit descriptions of particular aspects of the language in the form of a rule-based intonation course to make them aware of the intonation structures of Italian and train them in listening analytically to pitch phenomena. During the first term students learnt how to use speech analysis tools for perception and production of Italian prosody and intonation. Students were first introduced to the communicative situation through a multimedia text comprising a specific intonation pattern and were asked to understand the global meaning of the multimedia text. In the discrimination stage there was a more accurate comprehension of both text and intonation pattern. Students were then guided towards a more independent use of certain expressions. The practice was realized through embedded tools in NUI Blackboard and with the support of other tools, online or desktop, among which some social networks and virtual learning environments.

\subsection{The experiment}

Each learning unit comprised two perception exercises about intonational pattern, pitch accents, boundary tones, and word stress. Students would then receive automatic feedback with evaluations and solutions to wrong answers.

In the first week of the unit, students practiced the target sentences with the support of PRAAT. They were provided with both visual and auditory prompts, consisting 
of digitized versions of sentences spoken by two adult males, NSs of Italian. The subjects were asked to repeat each sentence after hearing the entire sequence. Then, they listened again to the sentences, watched the intonation curve, and imitated the target sentence, while the example and its incitation could be compared visually. Finally, they recorded and digitized their repetitions.

Comparing the visual waveform representation of their speech with that of the NS helped students match their pitch and intonation contours with those of the model (Anderson-Hsieh, 1992). In the second semester, students were directed towards oral production in specific linguistic contexts, by listening and then recording dialogues. The unit started with a narrative text, introducing students to the communicative situation that would be rehearsed in the next dialogue. After listening and comprehension, students were guided (imitation) towards an autonomous use of authentic spoken language segments.

The class was split into two groups, experimental (Exg) and control group $(\mathrm{Cg})$ : the Exg practiced dialogue with NSs in a very credible context ${ }^{6}$ and, playing the part of the dialogue's characters, re-used the previous sentences applying prosody and intonation while experiencing social interactions (Dell'Aria, 2013). In the Cg the dialogues were recorded separately: each learner submitted his/her part of the dialogue as an audio file. When files were joined, the resulting dialogues sounded "live", showing that training on phonological intonation helps to acquire the traits of real and meaningful communication acts.

\subsection{Testing procedure}

All participants made a pre-test two weeks before the experiment, in order to ensure that the target items were unknown. Immediate and delayed post-tests were administered after the treatment.

In group statistics the medians reveal that there is an improvement over time, although at the post-immediate point, scores were higher for the Exg than for the Cg. However, significantly, at the post-delayed point, scores were similar, proving that the effects of the activity were homogeneous in both groups. Therefore, comparing the results to pre-task performance, we can conclude that both conditions supported by speech analysis tools will result in retention of new prosodic schemes.

6. Some of these dialogues took place in the 3D virtual environment of Second Life. These sessions were done on a pilot basis with a small number of students who volunteered to take part. 
The figures below compare the intonation patterns in one of the NS' productions of a salutation ('Buon giorno' Figure 1) with corresponding sentences produced by the NNS, before (Figure 2) and after audio-visual feedback (Figure 3).

Figure 1. NS' production

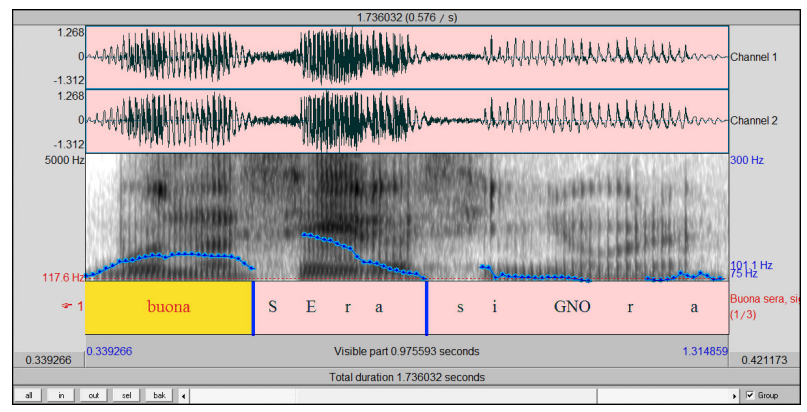

Figure 2. NNS' production

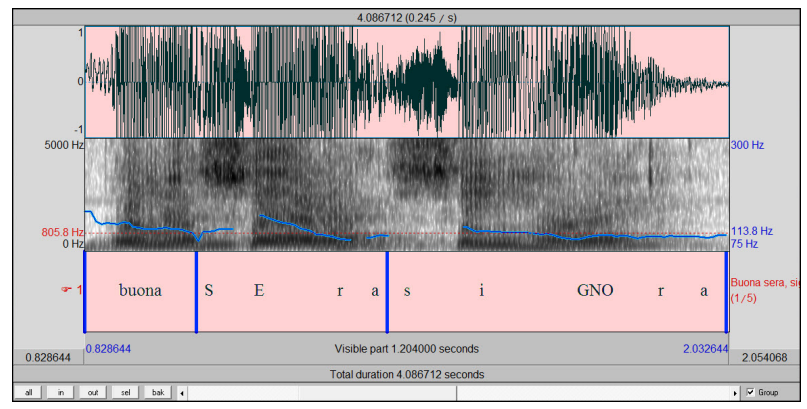

Figure 3. NNS' production

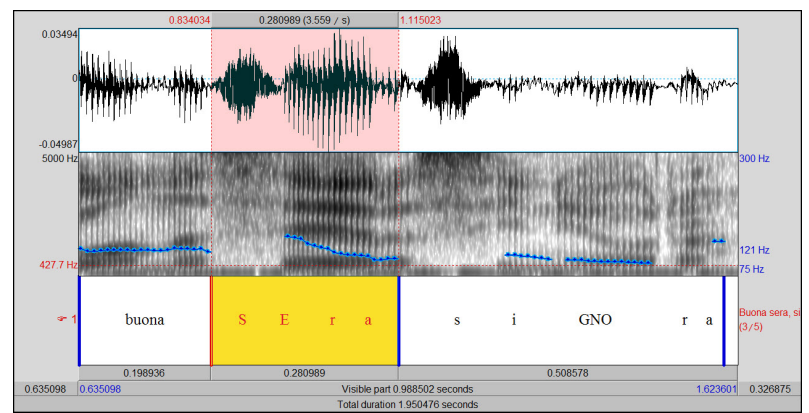


The figures reproduce the type of visualizations of the pitch patterns and sound waves of the speakers' utterances obtained with PRAAT.

\section{Conclusions}

The results of this small study indicate that using audio-visual feedback helps learners to improve their L2 productions and get closer to the target utterance with the help of an immediate and easy-to-read image of the differences existing between L1 and L2. The audio-visual feedback helps the NNSs to improve their Italian prosodic patterns considerably, to the point that the latter come to resemble closely those of the NS.

One of the difficulties that teachers face when adopting this method is the need to use clear and unambiguous phonetic material. Another problem is that the interpretation of the visual display must rely on teachers' knowledge of acoustic phonetics because most of the equipment on the market does not have these capabilities. This research supports the positive results obtained in similar studies which are being carried out on a variety of languages, indicating that speech-visualization technology is an effective pedagogical tool in the FL class.

Authors' comment: This paper is the result of the two researchers' shared reflections. The abstract and the paragraphs 1.1 and 2 are written by Dott.ssa Dell'Aria. The paragraphs 1, 1.2, and the conclusions are written by Dr Incalcaterra McLoughlin.

\section{References}

Anderson-Hsieh, J. (1992). Using electronic visual feedback to teach suprasegmentals. System, 20(1), 51-62. doi: 10.1016/0346-251X(92)90007-P

Bolinger, D. (1986). Intonation and its parts. Palo Alto, CA: Stanford University Press.

Chun, D. M. (1988). The neglected role of intonation in communicative competence and language proficiency. The Modern Language Journal, 72(3), 295-303. doi: 10.1111/j.1540-4781.1988. tb04192.x

Cruttenden, A. (1986). Intonation. Cambridge: Cambridge University Press.

Dell'Aria, C. (2013). Integrating the Real and Virtual World for Academic Language Education in Second Life. In P. Pumilia-Gnarini, E. Favaron, E. Pacetti, J. Bishop, \& L. Guerra (Eds.), Handbook of Research on Didactic Strategies and Technologies for Education: Incorporating Advancements (pp. 514-529). Hershey, PA: Information Science Reference. doi: 10.4018/978-1-4666-2122-0.ch045 
Dickerson, W. B. (1989). Stress in the stream of speech: The Rhythm of Spoken English/Teacher's Manual. Urbana: University of Illinois Press.

Fletcher, J. D., \& Tobias, S. (2005). The multimedia principle. In R. E. Mayer(Ed.), The Cambridge handbook of multimedia learning (pp. 117-134). New York: Cambridge University Press.

Gilbert, J. B. (1984). Clear speech. New York: Cambridge University Press.

Gilbert, J. B. (1987). Pronunciation and listening comprehension. In J. Morley (Ed.), Current Perspectives on Pronunciation (pp. 33-39). Washington, D. C.: Teachers of English to Speakers of Other Languages.

Gomez, P., Álvarez, A., Martínez, R., Bobadilla, J., Bernal, J., Rodellar,V., \& Nieto, V. (2008). Applications of formant detection in language learning. In M. Holland \& P. Fisher (Eds.), The Path of Speech Technologies in Computer Assisted Language Learning. New York: Routledge.

Lieberman, P. (1967). Intonation, perception and language. Cambridge, MIT Press.

Mayer, R. E. (2001). Multimedia learning. New York: Cambridge University Press.

McNerney, M., \& Mendelson, D. (1987). Putting suprasegmentals in their place. TESL Talk, $17(1), 132-140$.

Pennington, M. C., \& Richards, J. C. (1986). Pronunciation revisited. TESOL Quarterly, 20(2), 207-225. doi: $10.2307 / 3586541$

Schmidt, R. (2001). Attention. In P. Robinson (Ed.), Cognition and Second Language Instruction (pp. 3-32). Cambridge: Cambridge University Press. 


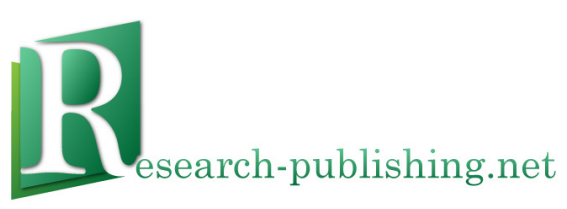

Published by Research-publishing.net

Dublin, Ireland; Voillans, France

info@research-publishing.net

(C) 2013 by Research-publishing.net

Research-publishing.net is a not-for-profit association

20 Years of EUROCALL: Learning from the Past, Looking to the Future.

2013 EUROCALL Conference, Évora, Portugal, Proceedings

Edited by Linda Bradley and Sylvie Thouësny

The moral right of the authors has been asserted

All articles in this book are licensed under a Creative Commons Attribution-Noncommercial-No Derivative Works 3.0 Unported License. You are free to share, copy, distribute and transmit the work under the following conditions:

- Attribution: You must attribute the work in the manner specified by the publisher.

- Noncommercial: You may not use this work for commercial purposes.

- No Derivative Works: You may not alter, transform, or build upon this work.

Research-publishing.net has no responsibility for the persistence or accuracy of URLs for external or thirdparty Internet websites referred to in this publication, and does not guarantee that any content on such websites is, or will remain, accurate or appropriate. Moreover, Research-publishing.net does not take any responsibility for the content of the pages written by the authors of this book. The authors have recognised that the work described was not published before (except in the form of an abstract or as part of a published lecture, or thesis), or that it is not under consideration for publication elsewhere. While the advice and information in this book are believed to be true and accurate on the date of its going to press, neither the authors, the editors, nor the publisher can accept any legal responsibility for any errors or omissions that may be made. The publisher makes no warranty, expressed or implied, with respect to the material contained herein.

Trademark notice: product or corporate names may be trademarks or registered trademarks, and are used only for identification and explanation without intent to infringe.

Copyrighted material: every effort has been made by the editors to trace copyright holders and to obtain their permission for the use of copyrighted material in this book. In the event of errors or omissions, please notify the publisher of any corrections that will need to be incorporated in future editions of this book.

Typeset by Research-publishing.net

Cover design: (C) Raphaël Savina (raphael@savina.net)

Photos: (c) Fany Savina (fany.savina@gmail.com)

Fonts used are licensed under a SIL Open Font License

ISBN13: 978-1-908416-12-4 (Paperback, Print on Demand, Lulu.com)

ISBN13: 978-1-908416-13-1 (Ebook, PDF file, Open Access, Research-publishing.net)

ISBN13: 978-1-908416-14-8 (Ebook, Kindle Edition, Amazon Media EU S.à r.1.)

ISBN13: 978-1-908416-15-5 (Ebook, ePUB file, Open Access, Research-publishing.net)

Legal deposit, Ireland: The National Library of Ireland, The Library of Trinity College, The Library of the University of Limerick, The Library of Dublin City University, The Library of NUI Cork, The Library of NUI Maynooth, The Library of University College Dublin, The Library of NUI Galway.

Legal deposit, United Kingdom: The British Library.

British Library Cataloguing-in-Publication Data.

A cataloguing record for this book is available from the British Library.

Legal deposit, France: Bibliothèque Nationale de France - Dépôt légal: novembre 2013. 